\title{
Antiplatelet Management for Stent-Assisted Coiling and Flow Diversion of Ruptured Intracranial Aneurysms: A DELPHI Consensus Statement
}

(D).M. Ospel, (D). Brouwer, (DF. Dorn, (D) A. Arthur, (D) M.E. Jensen, (DR. Nogueira, (DR. Chapot, (D). Albuquerque, (DC. Majoie, (D) Jayaraman, (D) A. Taylor, (D). Liu, (D). Fiehler, (D) N. Sakai, (D). Orlov, (DD. Kallmes, (D).F. Fraser, (D). Thibault, and

(D) M. Goyal

\begin{abstract}
BACKGROUND AND PURPOSE: There is a paucity of data regarding antiplatelet management strategies in the setting of stentassisted coiling/flow diversion for ruptured intracranial aneurysms. This study aimed to identify current challenges in antiplatelet management during stent-assisted coiling/flow diversion for ruptured intracranial aneurysms and to outline possible antiplatelet management strategies.
\end{abstract}

MATERIALS AND METHODS: The modified DELPHI approach with an on-line questionnaire was sent in several iterations to an international, multidisciplinary panel of 15 neurointerventionalists. The first round consisted of open-ended questions, followed by closed-ended questions in the subsequent rounds. Responses were analyzed in an anonymous fashion and summarized in the final manuscript draft. The statement received endorsement from the World Federation of Interventional and Therapeutic Neuroradiology, the Japanese Society for Neuroendovascular Therapy, and the Chinese Neurosurgical Society.

RESULTS: Data were collected from December 9, 2019, to March 13, 2020. Panel members achieved consensus that platelet function testing may not be necessary and that antiplatelet management for stent-assisted coiling and flow diversion of ruptured intracranial aneurysms can follow the same principles. Preprocedural placement of a ventricular drain was thought to be beneficial in cases with a high risk of hydrocephalus. A periprocedural dual, intravenous, antiplatelet regimen with aspirin and a glycoprotein IIb/IIla inhibitor was preferred as a standard approach. The panel agreed that intravenous medication can be converted to oral aspirin and an oral P2Y12 inhibitor within 24 hours after the procedure.

CONCLUSIONS: More and better data on antiplatelet management of patients with ruptured intracranial aneurysms undergoing stent-assisted coiling or flow diversion are urgently needed. Panel members in this DELPHI consensus study preferred a periprocedural dual-antiplatelet regimen with aspirin and a glycoprotein IIb/IIla inhibitor.

ABBREVIATION: GPIIb/IIla = glycoprotein IIb/IIla receptor

Received May 13, 2020; accepted after revision June 30.

From the Departments of Clinical Neurosciences (J.M.O., M.G.) and Diagnostic Imaging (M.G.), University of Calgary, Calgary, Alberta, Canada; Department of Radiology (J.M.O.), University Hospital of Basel, Basel, Switzerland; Department of Interventional Neuroradiology (P.B.), Karolinksa Hospital, Stockholm, Sweden; University NeuroVascular Center (P.B.), Leiden University Medical Center, Haaglanden Medical Center, Leiden, the Netherlands; Institute of Neuroradiology (F.D.), University of Bonn, Bonn, Germany; Department of Neurosurgery (A.A.), Semmes-Murphey Clinic/University of Tennessee, Memphis, Tennessee; Departments of Neurological Surgery, Radiology and Medical Imaging (M.E.J.), University of Virginia Health, Charlottesville, Virginia; Marcus Stroke \& Neuroscience Center (R.N.), Grady Health System, Atlanta, Georgia; Department of Neurology (R.N.), Emory University School of Medicine, Atlanta, Georgia; Department of Neuroradiology (R.C.), Alfred Krupp Krankenhaus Essen, Essen, Germany; Department of Neurosurgery (F.A.), Barrow Neurological Institute, Phoenix, Arizona; Department of Radiology (C.M.), Academic Medical Center, Amsterdam, the Netherlands; Departments of Diagnostic Imaging, Neurology, and Neurosurgery (M.J.), Warren Alpert School of Medicine at Brown University, Providence, Rhode Island; Groote Schuur Hospital (A.T.), University of Cape Town,
Cape Town, South Africa; Department of Neurosurgery (J.L.), Changhai Hospital Naval Medical University, Shanghai, China; Department of Diagnostic and Interventional Neuroradiology (J.F.), University Medical Center HamburgEppendorf, Hamburg, Germany; Department of Neurosurgery (N.S.), Kobe City Medical Center General Hospital, Kobe, Japan; Meshalkin National Medical Research Center (K.O.), Novosibirsk, Russian Federation; Department of Radiology (D.K.), Mayo Clinic, Rochester, Minnesota; Departments of Neurosurgery, Neurology, Radiology, and Neuroscience (J.F.F.), University of Kentucky, Lexington, Kentucky; and Member of the Scientific Committee of the World Federation of Interventional and Therapeutic Neuroradiology (L.T.)

Please address correspondence to Mayank Goyal, MD, Departments of Radiology and Clinical Neurosciences, Foothills Medical Centre, 1403 29th St. NW, Calgary, AB, T2N2T9; e-mail: mgoyal@ucalgary.ca; @johanna_ospel; @mayank_G0

Indicates article with supplemental on-line appendix and table.

Indicates article with supplemental on-line photos.

http://dx.doi.org/10.3174/ajnr.A6814 
A growing number of ruptured intracranial aneurysms are treated with endovascular techniques. ${ }^{1-3}$ While open surgical techniques remain a viable option for treating ruptured aneurysms, the availability and dissemination of endovascular devices and techniques are increasing. Wide-neck and fusiform aneurysms often require permanent placement of either a stent (ie, stent-assisted coiling) or a flow diverter. However, the increased thrombogenicity of such devices requires dual-antiplatelet therapy. This is less problematic in patients with unruptured intracranial aneurysms; but, in patients with ruptured aneurysms, physicians must weigh the risk of thrombotic complications against the risk of rebleeding. There is a relative paucity of data on antiplatelet management for stent-assisted coiling/flow diversion of ruptured intracranial aneurysms. Antiplatelet regimens reported in the literature vary widely, both for flow diversion ${ }^{4}$ and stent-assisted coiling, ${ }^{3,5-8}$ and they are based on nonrandomized, retrospective single-center studies. Providing practical guidance for physicians based on the limited available data is challenging and is further complicated by the differences in availability and access to certain antiplatelet agents, dependent on the jurisdiction/region of practice.

Furthermore, platelet-function testing has recently become available in clinical routine, and it has raised hopes for individually tailored and more effective antiplatelet management strategies. Platelet function testing is increasingly used in the elective setting, but its reliability and clinical impact remain controversial. ${ }^{9,10}$ A recent meta-analysis on patients treated with flow diversion showed that platelet-function testing is associated with worse rather than improved outcomes, ${ }^{9}$ possibly because its results might lead to rapid and haphazard alterations in medication. Platelet-function testing would also introduce additional treatment delays. Its value in the setting of ruptured intracranial aneurysms is, therefore, uncertain.

Whether and when to place a ventricular drain when treating ruptured intracranial aneurysms is another controversial topic, for which there are no uniform recommendations. ${ }^{4}$ Some physicians favor a low threshold for preprocedural placement of a ventricular drain because placement in the postprocedural period, after antiplatelet medication has been initiated, is associated with a higher risk of hemorrhagic complications. Others have found no association between the timing of antiplatelet medication in relation to ventricular drain placement and hemorrhagic complications. ${ }^{11}$ Given the lack of evidence for antiplatelet management of stent-assisted coiling/flow diversion in ruptured intracranial aneurysms, most physicians extrapolate their experience from unruptured cases and base their management decisions on personal experience and the local circumstances (access to and cost of antiplatelet agents).

\section{MATERIALS AND METHODS Literature Search}

In preparation for the DELPHI process, a MEDLINE literature search of English language articles containing the search terms "antiplatelet," "stent placement," "flow diversion," and "ruptured intracranial aneurysm" was performed for articles from January 2006 to December 2019. Bibliographies of relevant publications were screened to identify further studies of interest. Relevant articles were embedded in the respective survey questions and the full text articles distributed to the panel members. The On-line Table provides an overview of the key studies that were identified and used as a basis for the panel consensus on antiplatelet agents and dosage.

\section{Panel Members and DELPHI Methodology}

We formed a panel of 15 neurointerventionalists and used a modified DELPHI approach (https://www.rand.org/topics/delphimethod.html) as an attempt to provide a preliminary framework and practical guidance for antiplatelet management for stentassisted coiling/flow diversion in ruptured intracranial aneurysms until more data become available that allow evidence-based recommendations. The panel members in this study were experienced neurointerventionalists with high clinical and academic expertise in aneurysm treatment (15 neurointerventionalists affiliated with interventional neuroradiology, neurosurgery, and neurology from 8 countries). A list of the panel members can be found in the On-line Appendix. In addition, a pharmacology expert (L.T.) and an additional neurointerventional consultant with long-standing expertise in endovascular aneurysm treatment (R.C.) were consulted and provided feedback.

\section{DELPHI Methodology}

The DELPHI method is a systematic, interactive forecasting method that was originally developed to predict the impact of technology on warfare during the cold war. ${ }^{12}$ The underlying assumption is that in the absence of reliable data, forecasts or judgments from a structured, selected panel of experts are more accurate than estimates from individuals or unstructured groups. A selected group of individuals with high expertise in the area of interest undergoes a series of questionnaires with controlledopinion feedback; the final goal is to reach a group consensus. The method has been successfully implemented in health care research and is often used to standardize patient care in areas with a relative paucity of data until reliable evidence becomes available. ${ }^{13}$ In this study, the DELPHI technique was applied to generate a framework for antiplatelet management in the setting of stent-assisted coiling and flow diversion for unruptured intracranial aneurysms, an area in which evidence-based recommendations are not possible due to the limited body of literature. Figure 1 outlines the principal steps of the DELPHI approach as it was performed in this panel. ${ }^{14}$

\section{Data Collection and Analysis}

Anonymity was ensured through personalized links sent via an on-line response system (Qualtrics.com), in which panel members responded independent of each other to subsequent iterations of survey rounds. The first round contained exclusively open-ended questions. Answers from this initial round were analyzed in an affinity diagram (On-line Fig 2) and formed the basis for the following rounds, which consisted of closed-ended questions. Results from the previous DELPHI survey round were returned to the group during the next round in the form of statistical summaries, without attributing specific responses 


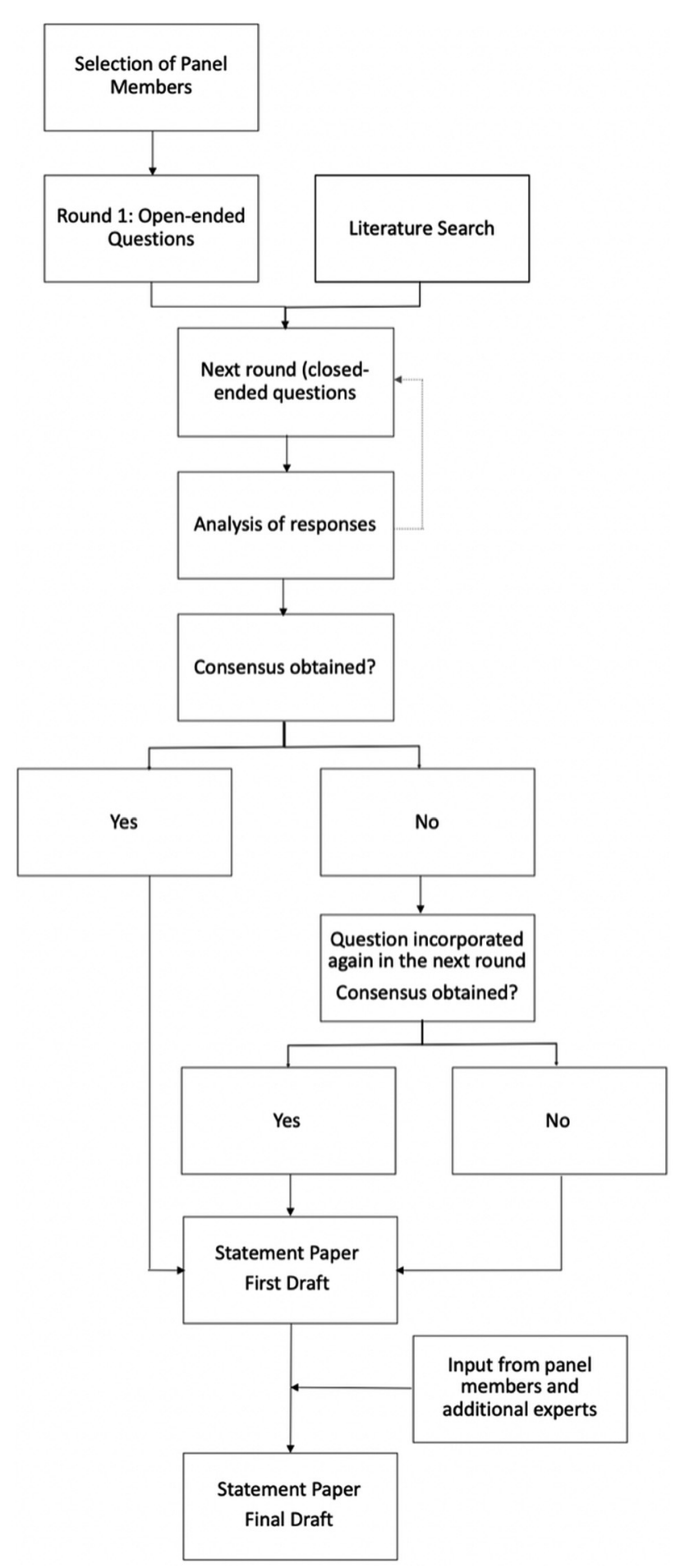

FIG 1. Flow chart of the modified DELPHI process as it was used in this study.

to individuals. At the final stage, group responses were assessed for consensus.

\section{RESULTS}

Response data were collected from December 2019 to March 2020. All 15 panel members completed a total of 6 survey rounds. The results were then summarized in a first draft, which was circulated among the panel members and the additional expert for discussion. The received feedback was incorporated in the final statement draft. The statement was endorsed by the World Federation of Interventional and Therapeutic Neuroradiology, the Japanese Society for Neuroendovascular Therapy, and the Chinese Neurosurgical Society.

\section{Preprocedural Management: Ventricular Drains}

In line with a recent meta-analysis, ${ }^{15}$ panel members agreed that in scenarios with manifest hydrocephalus or a high risk thereof (eg, patients with subarachnoid hemorrhage World Federation of Neurosurgical Societies grade III or higher, Fisher grade 3 or higher, intraparenchymal hemorrhage, Glasgow Coma Scale of $\leq 10$ ), it is worth considering placement of a ventricular drain before the procedure, even if the hydrocephalus is not manifest at the time of decision-making. In cases with no manifest hydrocephalus and a low risk thereof (eg, patients with subarachnoid hemorrhage World Federation of Neurosurgical Societies grade I, Fisher grade 1, Glasgow Coma Scale of 10-15), preprocedural placement of a ventricular drain might not be necessary. No consensus was achieved for cases with an intermediate risk of hydrocephalus (eg, patients with subarachnoid hemorrhage, World Federation of Neurosurgical Societies grade III, Fisher grade 4, Glasgow Coma Scale of 10-15, and small intraparenchymal hemorrhage but no hydrocephalus).

\section{Preprocedural Management: Platelet Function Testing}

There was consensus that routine platelet-function testing before the initiation of antiplatelet therapy for stent-assisted coiling/flow diversion of ruptured intracranial aneurysms may not be necessary.

\section{Dual-Antiplatelet Regimen}

The panel agreed that antiplatelet management for stent-assisted coiling and flow diversion of ruptured intracranial aneurysms can be identical, and they favored a dual-antiplatelet regimen as a standard approach. Alterations based on device coating were thought to not be necessary because currently available data on antithrombogenic device coatings ${ }^{16,17}$ were considered insufficient to justify changes in antiplatelet therapy.

\section{First Antiplatelet Agent}

The panel agreed on intravenous aspirin being the first-line agent of choice whenever intravenous aspirin is available as a single 500-mg bolus. In case intravenous aspirin is not available, oral aspirin was thought to be a suitable alternative, with a loading dose of $75-325 \mathrm{mg}$ and a daily maintenance dose of $<100 \mathrm{mg}$. The panel members believed that oral aspirin should be administered as soon as possible to maximize the time between administration and deployment of the intravascular device. For patients with reduced levels of consciousness or intubated patients, rectal aspirin $(120-300 \mathrm{mg})$ may be used as an alternative to intravenous aspirin.

\section{Second Antiplatelet Agent}

The panel members agreed on a glycoprotein IIb/IIIa receptor (GPIIb/IIIa inhibitor; abciximab, eptifibatide, tirofiban) as the second antiplatelet agent of choice. They favored a dosing scheme 
Table 1: Consensus recommendations for the dosage of GPIIb/IIla receptor inhibitors ${ }^{18-26}$

\begin{tabular}{llll}
\hline \multicolumn{1}{c}{ Agent } & \multicolumn{1}{c}{ Tirofiban } & \multicolumn{1}{c}{ Eptifibatide } & \multicolumn{1}{c}{ Abciximab } \\
\hline Loading dose (IV or IA bolus) & $12 \mathrm{mcg} / \mathrm{kg}$ for $30 \mathrm{~min}^{\mathrm{a}}$ & $180 \mathrm{mcg} / \mathrm{kg}$ for $1-2 \mathrm{~min}$ & $0.25 \mathrm{mg} / \mathrm{kg}$ \\
Maintenance dose (if necessary, IV infusion for 12-24 hours) & $0.1 \mathrm{mcg} / \mathrm{kg} / \mathrm{min}$ & $2 \mathrm{mcg} / \mathrm{min}$ & $0.125 \mathrm{mcg} / \mathrm{kg} / \mathrm{min}$ \\
Trade name & Aggrastat & Integrilin & ReoPro \\
Duration of antiplatelet effect & $4-8$ hours & 4 hours & 48 hours \\
\hline
\end{tabular}

Note:-IA indicates intra-arterial.

${ }^{\mathrm{a}} 0.4 \mathrm{mcg} / \mathrm{kg} / \mathrm{min}$.

Table 2: Consensus recommendations for dosing of oral P2Y12 inhibitors in the postprocedural period ${ }^{24,27}$

\begin{tabular}{llll}
\hline \multicolumn{1}{c}{ Agent } & Clopidogrel $^{\mathrm{a}}$ & \multicolumn{1}{c}{ Ticagrelor } & \multicolumn{1}{c}{ Prasugrel } \\
\hline Loading dose $^{\mathrm{b}}$ & $600 \mathrm{mg}$ & $180 \mathrm{mg}$ & $40-60 \mathrm{mg}$ \\
Maintenance dose & $75 \mathrm{mg}$ daily & $60-90 \mathrm{mg} \mathrm{2 \times /day}$ & $5-10 \mathrm{mg}$ daily \\
Trade name & Plavix & Brilinta/Brilique & Effient \\
Onset of action & 2 hours & $30 \mathrm{~min}$ & $15-30 \mathrm{~min}$ \\
\hline
\end{tabular}

a The panel favored clopidogrel as the oral P2Y12 inhibitor of choice in the postprocedural period after discontinuation of the GPIIb/IIla inhibitor but acknowledged that in case of known clopidogrel resistance, an alternative P2Y12 inhibitor may be chosen and that evidence from unruptured intracranial aneurysm treatment might suggest a superior safety profile of prasugrel compared with clopidogrel in the acute phase. ${ }^{28}$ It was thought that in cases in which ticagrelor was administered in the periprocedural period, it could be continued beyond the periprocedural period, depending on the cost and availability of different agents.

b If deemed necessary.

that consists of an initial bolus, followed by an infusion if necessary (see Table 1 for dosing schemes), whereby the choice of the GPIIb/IIIa inhibitor will likely depend on the local availability of certain agents. The panel also acknowledged that with increasing availability of intravenous cangrelor, the periprocedural antiplatelet regimen might change. In case GPIIb/IIIa inhibitors are not available, ticagrelor was favored as an alternative second agent, with an oral loading dose of $180 \mathrm{mg}$, followed by a twice-daily 60 to 90 -mg maintenance dose.

\section{Timing of Device Placement}

Panel members agreed that intracranial devices (stents, flow diverters) can probably be placed immediately after antiplatelet therapy has been initiated. Once the intention to treat a patient with a ruptured intracranial aneurysm with stentassisted coiling or flow diversion is clear, the antiplatelet medication can be initiated immediately. In an optimal scenario, the time gap between administration of an intravenous agent and device placement would be as long or longer than the time to onset of action of the agent. However, the panel agreed that if the time gap is shorter than the time to onset of action, it might be reasonable to proceed with the procedure; a waiting period between administration of the antiplatelet agents and device placement was not considered obligatory in such cases.

\section{Intraprocedural Thrombotic Complications}

The panel recommended that any filling defect in a vessel should raise the suspicion of a thrombotic complication and trigger treatment. Intraprocedural thrombotic complications may be managed with intra-arterial or additional intravenous infusion of GPIIb/IIIa inhibitors. At the same time, the panel members acknowledged that the occurrence of thrombotic complications will be very rare with a GPIIb/IIIa inhibitor as 1 of the 3 first-line antiplatelet agents.

\section{Postprocedural Management: Transition to Oral Antiplatelet Agents}

There was consensus that the periprocedural intravenous antiplatelet regimen can be converted to an oral regimen within 24 hours after the procedure in patients who can be clinically monitored (in intubated patients, one may consider continuing the intravenous scheme longer because the reliability of oral medication when administered via a nasogastric tube can be poor). Oral aspirin (75- to 325-mg loading dose, followed by a $<100$-mg daily maintenance dose) can thereby replace intravenous aspirin. The second intravenous agent may be converted to an oral P2Y12 inhibitor (see Table 2 for dosing schemes).

\section{Postprocedural Management: Platelet-Function Testing}

Panel members agreed that routine platelet-function testing after stent-assisted coiling/flow diversion for ruptured intracranial aneurysms may not be necessary.

Figure 2 summarizes the panel consensus for antiplatelet management for stent-assisted coiling/flow diversion of ruptured intracranial aneurysms.

\section{DISCUSSION}

This DELPHI consensus study identifies current challenges and suggests a possible approach to antiplatelet management for stentassisted coiling/flow diversion in ruptured intracranial aneurysms until sufficient evidence becomes available, and it encourages further research in this regard. While the DELPHI panel in this study acknowledged the potential advantages of antiplatelet testing, panel members mostly believed that platelet-function testing in its current form may not be necessary, possibly reflecting the lack of standardization and prevailing uncertainty regarding the value of currently available platelet-function tests. ${ }^{9,10}$ In fact, a recent meta-analysis showed that platelet-function testing before flow-diverter treatment for intracranial aneurysms in the elective setting might be associated with worse outcomes. ${ }^{9}$ There clearly seems to be a need for faster and more standardized platelet-function tests and more reliable data on the clinical impact of the test results for the theoretic benefits to translate into clinical practice. Panel members also believed that antiplatelet management for stentassisted coiling and flow diversion of ruptured intracranial aneurysms can follow the same principles, most likely because there are currently no studies that suggest otherwise.

AJNR Am J Neuroradiol 41:1856-62 Oct 2020 www.ajnr.org 


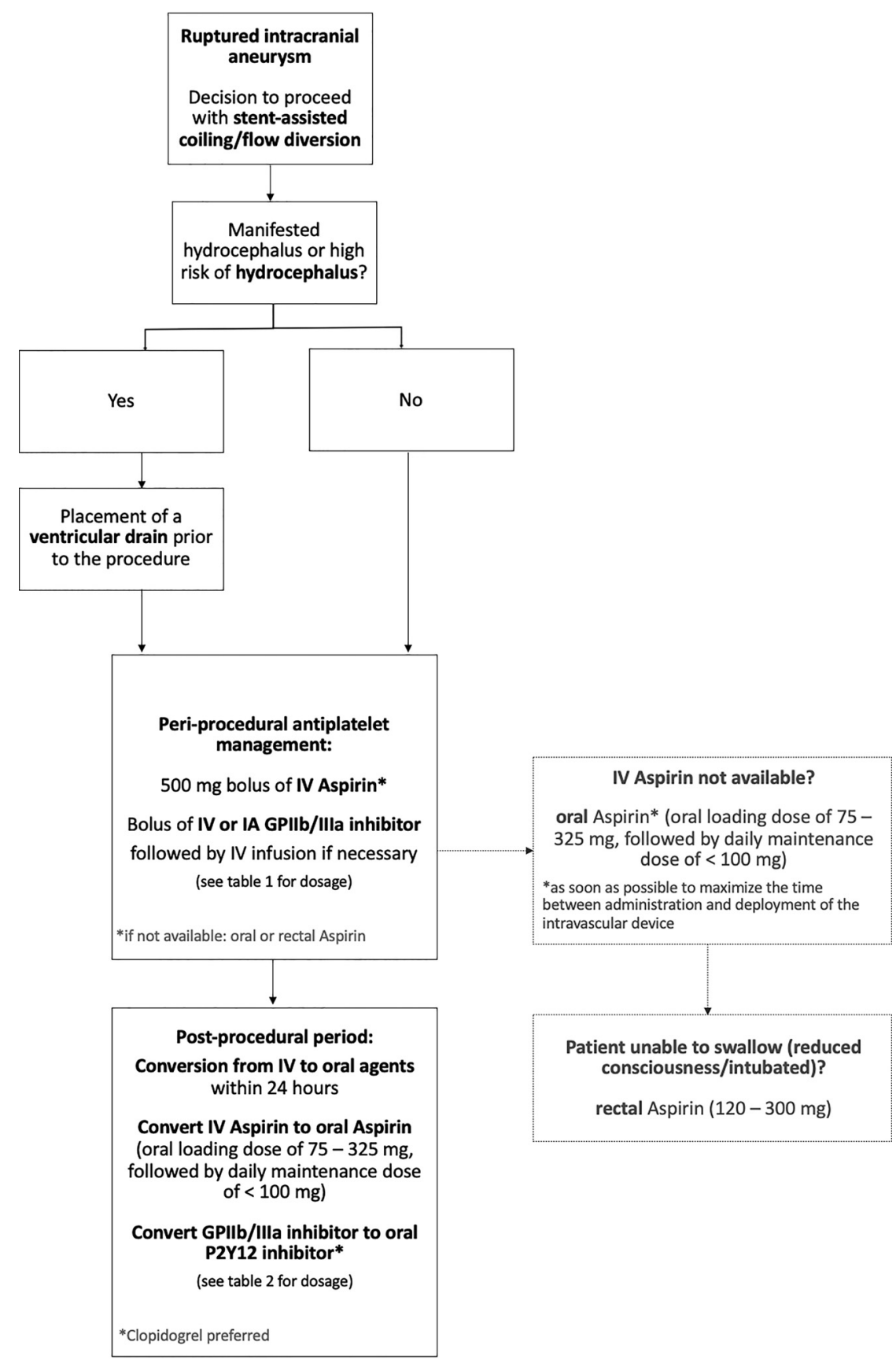

FIG 2. Summary of panel consensus for antiplatelet management for stent-assisted coiling/flow diversion of ruptured intracranial aneurysms.

The metal-coverage of flow diverters is, however, much higher compared with stents, and further research toward device-specific antiplatelet regimens as well as antithrombogenic surface coatings ${ }^{16,17}$ should be encouraged. A periprocedural, dual, intravenous, antiplatelet regimen with aspirin and a GPIIb/ IIIa inhibitor with conversion to oral aspirin and an oral P2Y12 inhibitor within 24 hours after the procedure was preferred as a standard approach. This regimen is very similar to the management of elective aneurysm treatment with stent-assisted coiling/ flow diversion in many places and was probably favored by most panel members due to the lack of large, inclusive studies focusing on patients with ruptured aneurysms. In the latter, conducting studies on antiplatelet therapy is much more difficult due to the emergent nature of the condition, but it would be of high importance to reduce variability and improve safety in antiplatelet management.

\section{Limitations}

The results of this study should not be misinterpreted as advocating stent-assisted coiling or flow diversion over surgical clipping, endosaccular treatments, or conservative therapy for any particular patient, nor is it intended to compete with or replace any future evidence-based recommendations. On the contrary, the authors and panel members believe that such data are urgently needed. The relatively low number of panel members could have resulted in personal biases in the presented recommendations, and region-specific 
peculiarities, such as limited or no access to certain agents, could not be taken into account. Furthermore, the considerations outlined in this perspective are a snapshot in time, as antiplatelet therapy and neurointerventional devices continue to evolve. With further advances in surface coatings of stents and flow diverters for instance, dual-antiplatelet therapy could soon become obsolete. Last, this DELPHI consensus statement focused on antiplatelet management in the acute phase; thus, considerations on the optimal timing for conversion from intravenous to oral agents were not addressed in depth nor were questions on ventricular drain removal, ventriculoperitoneal/ventriculoatrial shunts, and cases with simultaneous intraparenchymal hemorrhage.

\section{CONCLUSIONS}

Studies to determine the optimal antiplatelet regimen for stentassisted coiling and flow diversion in the setting of ruptured intracranial aneurysms are urgently needed. Panel members in this DELPHI consensus study preferred a periprocedural dual-antiplatelet regimen with aspirin and a GPIIb/IIIa inhibitor.

Disclosures: Johanna M. Ospel-UNRELATED: Grants/Grants Pending: Julia Bangerter Rhyner Foundation, University of Basel Research Foundation, Freiwiliige Akademische Gesellschaft Basel, Comments: research scholarships. Patrick Brouwer-UNRELATED: Consultancy: Cerenovus; Payment for Lectures Including Service on Speakers Bureaus: Cerenovus. Franziska DornUNRELATED: Consultancy: Cerus Endovascular, phenox, Balt; Payment for Lectures Including Service on Speakers Bureaus: speakers honoraria from Cerenovus and Acandis. Adam Arthur-UNRELATED: Consultancy: Balt, Cerenovus, Medtronic, MicroVention, Penumbra, Siemens, Stryker*; Stock/ Stock Options: Bendit, Cerebrotech, EndoStream, Magneto, Marblehead Medical, Neurogami, Serenity, Synchron, Triad Medical, Vascular Simulations. Mary E. Jensen-UNRELATED: Employment: University of Virginia Health System. Raul Nogueira-OTHER RELATIONSHIPS: Consulting Fees: Anaconda, Biogen, Cerenovus, Genentech, Imperative Care, Medtronic, phenox, Prolong Pharmaceuticals, Stryker Neurovascular; Stock/Stock Options: advisory roles with Astrocyte Pharmaceuticals, Brainomix, Cerebrotech, Ceretrieve, Corindus Vascular Robotics, Vesalio, Viz-Ai, and Perfuze. Rene Chapot-UNRELATED: Payment for Lectures Including Service on Speakers Bureaus: Balt, Medtronic, MicroVention, Siemens, Stryker*; Travel/Accommodations/ Meeting Expenses Unrelated to Activities Listed: Boston, Balt, MicroVention, Rapid Medical, Siemens. Charles Majoie-UNRELATED: Grants/Grants Pending: European Commission, Dutch Heart Foundation, Stryker*; Stock/ Stock Options: Nico.lab (modest), Comments: a company that focuses on the use of artificial intelligence for medical imaging analysis. Mahesh JayaramanUNRELATED: Consultancy: Medtronic, Comments: speaking for stroke systems of care at ISC 2018. Allan Taylor-UNRELATED: Employment: Groote Schuur Hospital, Comments: full-time employment with a public hospital; Expert Testimony: defense and prosecuting attorneys, Comments: I provide expert testimony in neuromuscular cases for 1 to 2 matters per year; Other: private practice, Comments: I have a limited private practice for patients with neuromuscular disease. Jens Fiehler-UNRELATED: Consultancy: Acandis, Cerenovus, Medtronic, MicroVention, Stryker, Penumbra; Grants/Grants Pending: Acandis, Cerenovus, Medtronic, MicroVention, Stryker*; Stock/Stock Options: Tegus; OTHER RELATIONSHIPS: Eppdata CEO. Nobuyuki SakaiUNRELATED: Grants/Grants Pending: Terumo, Medtronic, Comments: Modest*; Payment for Lectures Including Service on Speakers Bureaus: Biomedical Solutions, Stryker, Terumo.* Mayank Goyal-UNRELATED: Consultancy: Stryker, Medtronic, MicroVention, Mentice, Comments: advice on acute stroke intervention; Grants/Grants Pending: Medtronic, Stryker, Cerenovus, Comments: unrestricted research grants to University of Calgary*; Patents (Planned, Pending or Issued): GE Healthcare, Comments: licensing agreement: Systems of Acute Stroke Diagnosis; Royalties: GE Healthcare. Kirill Orlov-UNRELATED: Consultancy: Medtronic, MicroVention. Justin FraserUNRELATED: Board Membership: Cerelux; Consultancy: Medtronic, Penumbra, Stream; Grants/Grants Pending: American Heart Association, University of Kentucky; Stock/Stock Options: Fawkes Biotechnology. David Kallmes-UNRELATED: Grants/Grants Pending: MicroVention, NeuroSigma, Medtronic, Comments: funding for preclinical research*; Patents (Planned, Pending or Issued): Mayo Clinic, Comments: patent for protection device*;
Stock/Stock Options: Marblehead Medical, Superior Medical Experts. *Money paid to the institution.

\section{REFERENCES}

1. Hammer A, Steiner A, Kerry G, et al. Treatment of ruptured intracranial aneurysms yesterday and now. PLoS One 2017;12:e172837 CrossRef Medline

2. Howard BM, Frerich JM, Madaelil TP, et al. "Plug and pipe” strategy for treatment of ruptured intracranial aneurysms. J Neurointerv Surg 2019;11:43-48 CrossRef Medline

3. Zuo Q, Yang P, Lv N, et al. Safety of coiling with stent placement for the treatment of ruptured wide-necked intracranial aneurysms: a contemporary cohort study in a high-volume center after improvement of skills and strategy. J Neurosurg 2019;131:435-41 CrossRef Medline

4. Madaelil TP, Moran CJ, Cross DT 3rd, et al. Flow diversion in ruptured intracranial aneurysms: a meta-analysis. AJNR Am J Neuroradiol 2017;38:590-95 CrossRef Medline

5. Cai K, Ji Q, Cao M, et al. Association of different stenting procedures with symptomatic thromboembolic complications in stentassisted coiling of ruptured wide-necked intracranial aneurysms. World Neurosurg 2017;104:824-30 CrossRef Medline

6. Li C, Li Y. Stent-assisted coiling of ruptured wide-necked intracranial aneurysms. Interv Neuroradiol 2013;19:283-88 CrossRef Medline

7. Liu P, Lv X, Li Y, et al. Stent-assisted coiling of ruptured widenecked intracranial aneurysms: a single-center experience of 218 consecutive patients. Neurol India 2016;64(Suppl):S70-77 CrossRef Medline

8. Yang P, Zhao K, Zhou Y, et al. Stent-assisted coil placement for the treatment of 211 acutely ruptured wide-necked intracranial aneurysms: a single-center 11-year experience. Radiology 2015;276:54552 CrossRef Medline

9. Brinjikji W, Lanzino G, Cloft HJ, et al. Platelet testing is associated with worse clinical outcomes for patients treated with the Pipeline Embolization Device. AJNR Am J Neuroradiol 2015;36:2090-95 CrossRef Medline

10. Comin J, Kallmes DF. Platelet-function testing in patients undergoing neurovascular procedures: caught between a rock and a hard place. AJNR Am J Neuroradiol 2013;34:730-34 CrossRef Medline

11. Hudson JS, Prout BS, Nagahama Y, et al. External ventricular drain and hemorrhage in aneurysmal subarachnoid hemorrhage patients on dual antiplatelet therapy: a retrospective cohort study. Neurosurgery 2019;84:479-84 CrossRef Medline

12. Dayé C. How to train your oracle: the Delphi method and its turbulent youth in operations research and the policy sciences. Soc Stud Sci 2018;48:846-68 CrossRef Medline

13. Steurer J. The Delphi method: an efficient procedure to generate knowledge. Skeletal Radiology 2011;40:959-61 CrossRef Medline

14. Dalkey NC, Helmer-Hirschberg O. An Experimental Application of the Delphi Method to the Use of Experts. Rand; 1962

15. Cagnazzo F, Di Carlo DT, Petrella G, et al. Ventriculostomy-related hemorrhage in patients on antiplatelet therapy for endovascular treatment of acutely ruptured intracranial aneurysms: a metaanalysis. Neurosurg Rev 2020;43:397-406 CrossRef Medline

16. Manning NW, Cheung A, Phillips TJ, et al. Pipeline shield with single antiplatelet therapy in aneurysmal subarachnoid haemorrhage: multicentre experience. J Neurointerv Surg 2019;11:694-98 CrossRef Medline

17. Aguilar Perez M, AlMatter M, Hellstern V, et al. Use of the pCONus HPC as an adjunct to coil occlusion of acutely ruptured aneurysms: early clinical experience using single antiplatelet therapy. $J$ Neurointerv Surg 2020 Feb 26. [Epub ahead of print] CrossRef Medline

18. Kang HS, Kwon BJ, Roh HG, et al. Intra-arterial tirofiban infusion for thromboembolism during endovascular treatment of intracranial aneurysms. Neurosurgery 2008;63:230-37; discussion 237-38 CrossRef Medline 
19. Pandya DJ, Fitzsimmons BF, Wolfe TJ, et al. Measurement of antiplatelet inhibition during neurointerventional procedures: the effect of antithrombotic duration and loading dose. J Neuroimaging 2010;20:64-69 CrossRef Medline

20. Dumont TM, Kan P, Snyder KV, et al. Adjunctive use of eptifibatide for complication management during elective neuroendovascular procedures. J Neurointerv Surg 2013;5:226-30 CrossRef Medline

21. Brinjikji W, Morales-Valero SF, Murad MH, et al. Rescue treatment of thromboembolic complications during endovascular treatment of cerebral aneurysms: a meta-analysis. AJNR Am J Neuroradiol 2015;36:121-25 CrossRef Medline

22. Choi HH, Cho YD, Han MH, et al. Antiplatelet premedication-free stent-assisted coil embolization in acutely ruptured aneurysms. World Neurosurg 2018;114:e1152-60 CrossRef Medline

23. Choi HH, Lee JJ, Cho YD, et al. Antiplatelet premedication for stent-assisted coil embolization of intracranial aneurysms: low- dose prasugrel vs clopidogrel. Neurosurgery 2018;83:981-88 CrossRef Medline

24. Kim KS, Fraser JF, Grupke S, et al. Management of antiplatelet therapy in patients undergoing neuroendovascular procedures. J Neurosurg 2018;129:890-905 CrossRef Medline

25. Samaniego EA, Gibson E, Nakagawa D, et al. Safety of tirofiban and dual antiplatelet therapy in treating intracranial aneurysms. Stroke Vasc Neurol 2019;4:36-42 CrossRef Medline

26. Tonetti DA, Jankowitz BT, Gross BA. Antiplatelet therapy in flow diversion. Neurosurgery 2020;86:S47-52 CrossRef Medline

27. Fiorella D, Thiabolt L, Albuquerque FC, et al. Antiplatelet therapy in neuroendovascular therapeutics. Neurosurg Clin N Am 2005;16: 517-40, vi CrossRef Medline

28. Cagnazzo F, Perrini P, Lefevre PH, et al. Comparison of prasugrel and clopidogrel used as antiplatelet medication for endovascular treatment of unruptured intracranial aneurysms: a meta-analysis. AJNR Am J Neuroradiol 2019;40:681-86 CrossRef Medline 
n the articles "Antiplatelet Management for Stent-Assisted Coiling and Flow Diversion of Ruptured Intracranial Aneurysms: A

DELPHI Consensus Statement” (AJNR Am J Neuroradiol 2020;41:1856-62) and "Considerations for Antiplatelet Management of Carotid Stent Placement in the Setting of Mechanical Thrombectomy: A Delphi Consensus Statement" (AJNR Am J Neuroradiol 2020;41:2274-79), the dosage parameter of eptifibatide in Table 1 should have been $\mathrm{mcg} / \mathrm{kg} / \mathrm{min}$.

The authors regret the errors.

http://dx.doi.org/10.3174/ajnr.A7238 